\title{
CONGENITAL ABSENCE OF THE ABDOMINAL MUSCLES
}

BY

\section{LESLIE GEORGE HOUSDEN, M.D.}

In the most recent, authoritative, British text-book of diseases of infancy and childhood ${ }^{10}$, congenital absence of the abdominal muscles is dismissed in the following words:-

- Congenital absence of the abdominal muscles has also been recorded. In the case illustrated, the leathery, wrinkled appearance of the skin is seen. On palpation, the abdomen felt like a soft bag. The infant was extremely constipated and, being unable to cough properly, soon succumbed to pulmonary infection.'

This does not by any means, epitomize the whole story of a condition that has been very much recorded, especially in Germany. In the present monograph a new case is reported in detail and a discussion of the etiology of the condition follows a summary of the chief points of interest in the other thirty-three published cases.

\section{The Author's Case.}

Leslie B, a male infant, was born on August 13th, 1933, of normal healthy parents. The four grandparents were alive and well. There had been four previous normal, healthy children of the marriage, two boys, aged eleven and ten, and two girls, aged eight and five. There had been no miscarriages. The mother, aged 31, had suffered from influenza in January, 1933, but had otherwise enjoyed good health and the expected date of the birth was September 4th, twenty-two days later than the actual confinement. At the end of April the mother noticed that she became very big ' all of a sudden' and remained much about the same size until the end of the pregnancy. She had no abnormal urinary symptoms. At an ante-natal examination on June 14th, her girth was 39 inches and she was found to have a marked degree of hydramnios. At a further examination on July, 12th, the foetal heart was heard, but the foetal parts were difficult to palpate.

The birth was normal, presentation cephalic and the birth-weight $7 \frac{1}{2}$ pounds. There was an abnormal quantity of amniotic fluid and the infant passed an unusually large quantity of urine both before the placenta was born and again shortly afterwards. The midwife reported that there was considerable bleeding from the severed cord, although it was twice tied. Meconium was passed the same evening and again the following morning. The baby did not cough and his cry was short and faint-more of the nature of a squeak. He sucked strongly from birth.

On examination. The baby was examined about an hour after birth. He was well-nourished and had a covering of thick hair on his arms and legs and around the lumbar spinal region. His head, face and arms were normal, as were his legs, with the exception of a talipes equino-varus deformity of the right foot. The thorax was pigeon-chested and showed a well-marked eversion of both costo-chondral margins. On deep inspiration, the left side of the chest expanded more than the right. The skin of the posterior half of the penis below was continuous with that of the scrotum, and there was a hairy dimple at the lower end of the spine (spina bifida occulta). Neither testicle could be palpated in the scrotum or groin. There was no phimosis. The abdomen was flattened and bulged at the flanks, the skin 
being thin, wrinkled and loose and showing many folds. One central, longitudinal furrow, six inches long, extended from half an inch below the tip of the ensiform cartilage to the pre-pubic area, where it split into two short, diverging furrows. On either side of this was a shorter, longitudinal furrow. The bladder could be felt, as a hard tumour, extending upwards, beyond the umbilicus, to which it seemed to be attached. In size it was $3 \frac{1}{2}$ inches long by $2 \frac{3}{4}$ inches from side to side

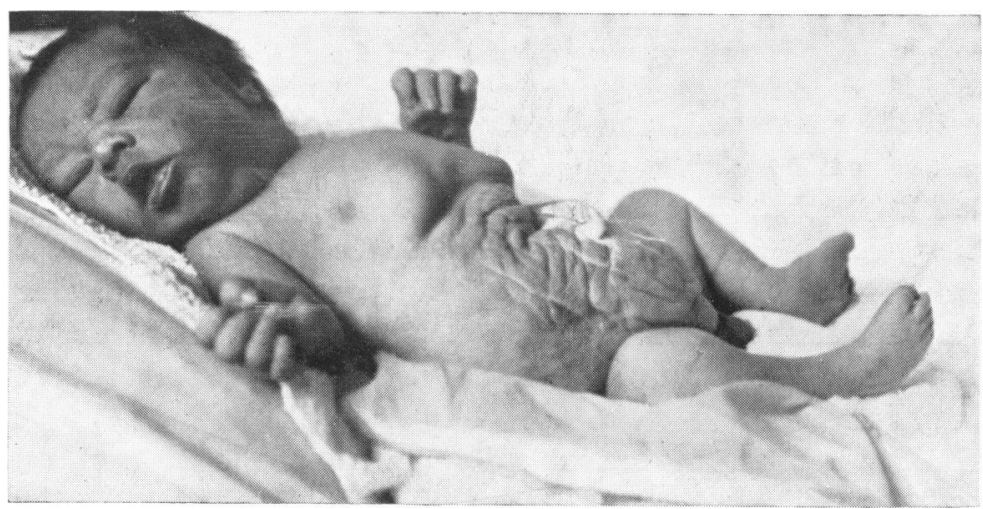

FIg. 1.-Leslie B., twenty-four hours old.

and, on being massaged, it was felt to harden like a pregnant uterus. With the baby in the recumbent position, it bulged well over the symphysis pubis. Intestinal peristalsis was seen in both flanks, being particularly well-marked on the right side. Both kidneys could be palpated and the liver was palpable from one to two fingersbreadths below the costal margin. The spleen could be felt behind the lower borders of the ribs.

Second day. After manipulation of the right foot, the baby gave a long, loud cry. Urine was passed this evening. Respirations 36,50 and 45 in successive minutes.

FIFTH DAY. Urine showed a faint haze of albumin. No sugar present. The centrifugalized deposit showed an occasional pus cell.

TENTH DAY. Baby doing well.

ELEventh DAY. The baby was taken to the local hospital for a radiographic examination. A catheter was passed with ease and eight ounces of urine were drawn off, an equal quantity of 20 per cent. sodium bromide being run into the

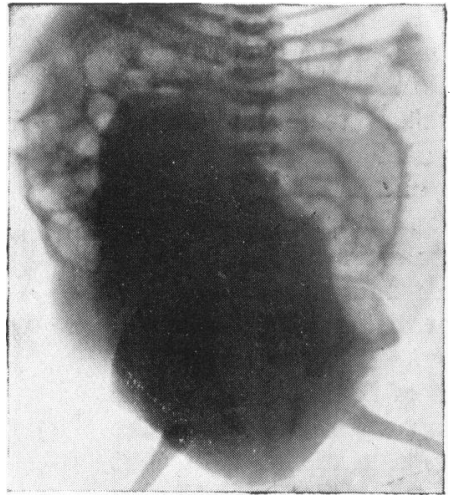

Fig. 2.-Skiagram of bladder, containing urine only.

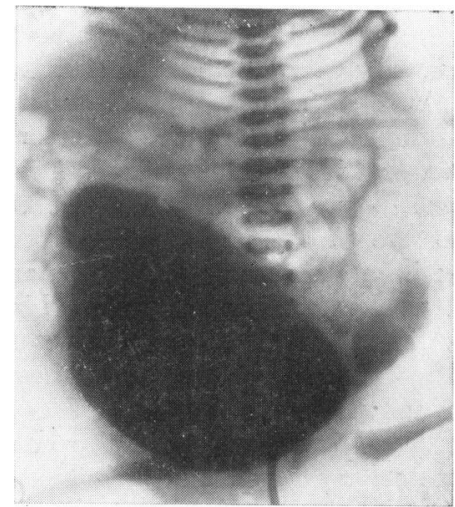

Fig. 3.-Bladder, containing five ounces of sodium bromide.

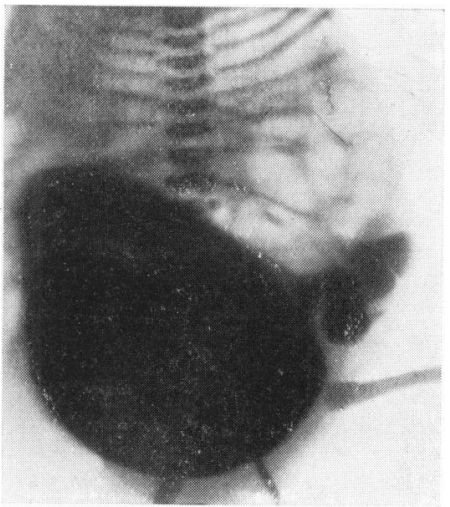

FIG. 4.-Bladder, containing eight ounces of sodium bromide. Right ureter containing sodium bromide, 
bladder in its place. The skiagrams were taken, one after five ounces and the other after eight ounces had been injected and these were compared with a previous skiagram, taken before catheterization. As will be seen from the reproductions given, the sodium bromide passed freely into the dilated right ureter. (The left ureter was probably hidden, by the inclination of the bladder to the left.) Immediately after the last skiagram had been taken, thirteen ounces of a mixture of sodium bromide solution and urine were withdrawn through the catheter by a syringeand more could have been obtained. An examination of some of the urine showed that the centrifugalized deposit consisted of a few non-motile rod bacilli. Neither corpuscles nor casts were seen.

TWELFTH DAY. At 7.30 a.m. the baby was found 'soaked' with normal-coloured urine, 'wetter than he had ever been before.' At 9 a.m. he was found to have passed blood-stained urine and this he continued to do, a little at a time, at frequent intervals. There were no blood-clots passed. At 11.30 a.m. his pulse-rate was 168 and his respirations 65. A breast-feed was given and the filling stomach could be faintly made out on palpation, but no gastric swelling was visible. The infant's abdomen seemed very depressed and subsided, particularly under the ribs and sternum.

Thirteenth DaY. Morning rectal temperature-101.6. Respirations 92. The baby was limper than before and passed some mucus per rectum. He had passed normal-coloured urine at frequent intervals, and was less willing to take the breast.

Seventeenth DAY. The rectal temperatures for the last few days had ranged from $100^{\circ}$ to $103^{\circ}$. The urine, passed frequently, was faintly pink and had an offensive smell. The nurse said that the baby lay on his right side whenever he could and that sometimes, when undressed, he bent backwards until his heels and occiput almost met. The baby was very lethargic.

Eighteenth DaY. Weight- 7 pounds. Temperature at noon $-98 \cdot 0^{\circ}$.

NinETEENTH DAY. The umbilical cord separated.

TwentY-FOURTH DAY. Weight -6 pounds 7 ounces. Baby taking practically nothing. Soon after starting to suck, bright, fresh blood appeared in his mouth and this blood did not come from the nipple or from any visible bleeding-point in the baby's mouth. Urine, thick and very offensive.

TWENTY-SIXTh DaY. Baby died from uraemia.

AUTOPSY (performed $3 \frac{1}{2}$ hours after death). General condition, lean, but not emaciated. The thorax was markedly 'pigeon-chested,' the diameter at the ribmargins being $14 \frac{1}{2}$ inches. The total length of the sternum was $2 \frac{7}{8}$ inches.

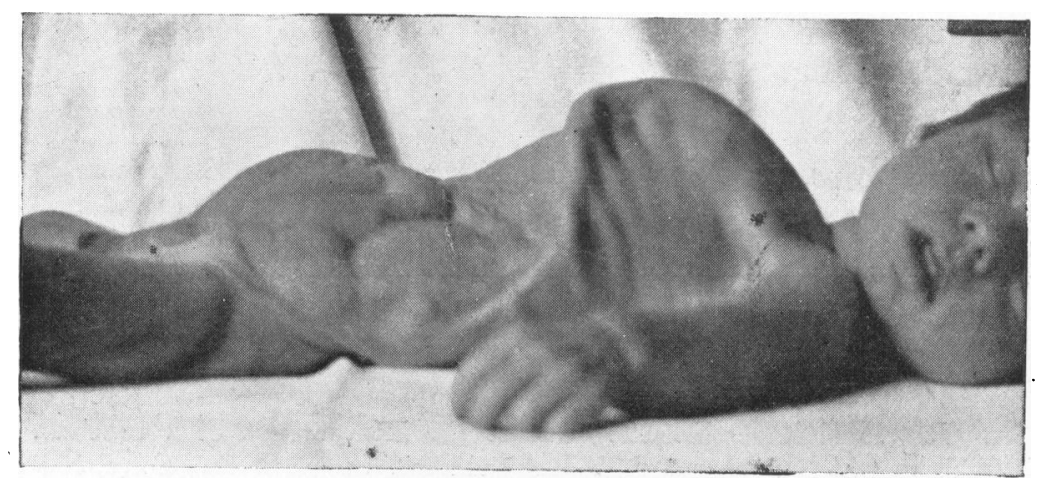

FIG. 5.-Leslie B., post mortem. The enlarged left ureter is clearly seen, as is the prominence of the dilated and hypertrophied bladder.

The abdomen was sunken and flattened and bulged at each side. The convoluted bowel, enlarged liver and gas-filled stomach were sharply defined beneath the wrinkled skin, in which were the three well-marked longitudinal furrows, already 
noticed in the description of the living infant and well shown in the photographs. The middle furrow was definitely serrated, especially above the umbilicus, which was closely adherent to the bladder though normal in other respects. The entire skin of the abdomen had the appearance of having been formerly much stretched.

A medial incision, avoiding the umbilicus, was made and the skin dissected back on each side, a section of considerable difficulty, owing to the intimate, fibrous adherence of the underlying aponeurosis. This aponeurosis was removed, with the exception of a small area around the umbilicus, from the thorax to the pubis longitudinally and, laterally, far round into the flanks. Lined, on its posterior surface, by peritoneum, it had a lace-like transparency, devoid of any trace of muscle. A very short, fusiform bundle of muscle-fibres was found attached to the eighth and ninth costal cartilages on the left side and this may have been part of the left external oblique muscle. Nowhere else could any evidence be found of the external or internal obliques, the transversales, the recti or the pyramidales muscles. Later, when all the abdominal viscera had been removed, no muscle could be recognised on either side, lateral to the psoas major. The quadrati lumborum seemed to be absent. No abnormalities were apparent in the diaphragm or pelvic muscles.

On removing the aponeurosis; the bladder was found to be a hard, fusiform organ, $3 \frac{1}{2}$ by $1_{4}^{\frac{1}{4}}$ inches, as seen from in front and $1 \frac{3}{4}$ inches in its antero-posterior

Right kidney.

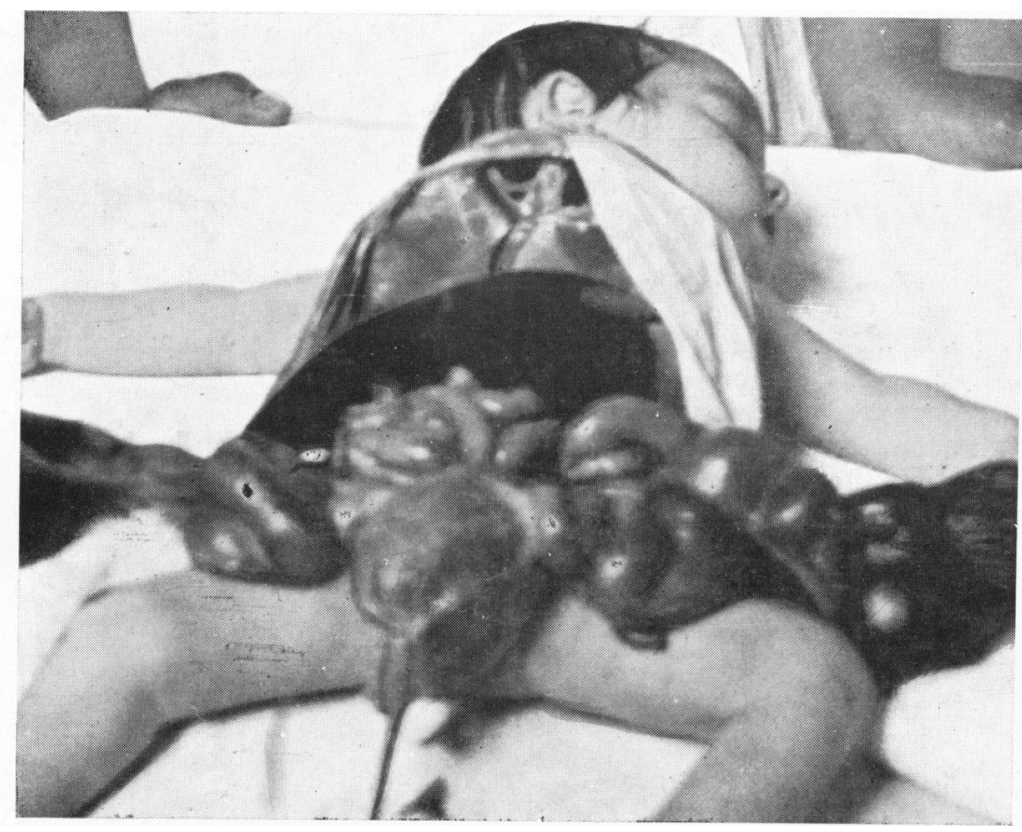

Left kidney.

Fig. 6.-Showing bladder, held forward by the patent umbilical vein. The great size of the ureters, compared witn the bowel, between
them, is well shown.

diameter. It was closely adherent, without the interposition of a urachus, to the umbilicus, from which a patent umbilical vein ran to the liver. On either side of the bladder each flank was filled by an enlarged and much convoluted, thin-walled ureter, each being considerably larger than any part of the intestine. Each increased in diameter from above downwards, the upper ends being of little more than normal width, while half-way down they had a diameter of from $1 \frac{1}{4}$ to $1 \frac{1}{2}$ inches. Each contracted again to some extent as it approached the bladder, which was entered on each side in the usual situation. Both kidneys were hydronephrotic, 
the dilatations affecting the calices and pelves. The right measured $3 \frac{1}{2}$ by $2 \frac{1}{2}$ inches and the left $2 \frac{1}{2}$ by 2 inches. On later section, the renal substance was found to have been reduced to about ${ }_{10}^{1}$ inch in thickness.

Each testicle was attached by a peritoneal fold to the convoluted ureter of the same side, about an inch above its termination, the vasa deferentia passing downwards, on the ureters and posterior surface of the bladder, to open into the urethra in the usual situation.

Ten ounces of water was injected into the bladder through a catheter and was found to pass easily into the left ureter, but less readily through the right ureteric opening.

The bladder wall was hypertrophied and had an almost uniform thickness of $\frac{3}{8}$ inch. The mucosa was inflamed and thickened and had some adherent muco-pus. The prostatic urethra was dilated in its upper part, above the verumontanum, so that it had the appearance of forming the lower segment of the bladder; its wall here was hypertrophied to $\frac{1}{6}$ inch in thickness. The lower part of the prostatic urethra and the membranous urethra were not dilated, but the wall of the former was hypertrophied. The wall of the membranous part was little, if at all, thickened. Projecting into the lumen, from the anterior wall of the lower part of the prostatic urethra was a prominent, longitudinal ridge, about $1 \mathrm{~cm}$. long. Narrow and tapering posteriorly, this ridge became wider anteriorly, reaching a maximum width of $2.5 \mathrm{~mm}$.

No abnormalities were discovered in the suprarenal glands, the liver, spleen or bowel and the stomach was normal, but contained bile and a little altered blood.

The rest of the body was not examined.

\section{Summary of published cases.*}

Total Number of cases. Thirty-four.

SEx. Male, 28. Female, 1. Unstated, 3.

AGE. Eighteen of the cases died, the eldest at eighteen months. Of the rest, one was alive at 70 (15), one at 60 (17), two at 17 (8 and 30), one at $15(16)$, one at $6(7)$, one at $2(6)$ and seven at ages under one year.

Causes of peath. Six infants died from pneumonia $(13,17,21,23,24$ and 29), two from uraemia (27 and 34), and one each from collapse and emphysema of the lungs (4), exhaustion and wasting (5), erysipelas (9), intercurrent disease (10), suppurative pericarditis (11), entero-colitis (20) and dermatitis exfoliativa neonatorum (33). Three died from unspecified causes.

Family history. In the thirteen cases where the family history is given, parents, grand-parents, brothers and sisters had been healthy and without congenital abnormalities. In some cases, the affected infant was the first of the family, in others, he was the seventh, eighth or eleventh. In one case (25), both mother and child were syphilitic, but in two cases (26 and 33), where the matter is mentioned, the mother's Bordet-Wassermann reaction was negative.

* In this summary and in the discussion that follows, the numbers in brackets refer to the published cases, short accounts of which have had to be omitted from the present communication, owing to lack of space. In most cases the numbers also refer to the references, the exceptions being cases (9) and (10) are reported under reference 9, case (11) under references 11 and 12, cases (13) and (14) under reference 13 , cases (29), (30) and (31) under reference 29 , case (32) under reference 30, case (33) under reference 31, while (34) is the author's case. The two earliest reports were too incomplete to be included in the summary. 
Obstetrical History. In fourteen cases, the pregnancy is stated to have been at full-term at the onset of parturition and, in two other cases to have been at seven and eight months respectively. Three times the amount of liquor amnii is mentioned. Once it was scanty (14), once there was hydramnios (32) and in the third case, there was no hydramnios (17).

Autopsies. These were held in fourteen cases.

Chest deformities. In ten cases $(7,8,9,13,17,21,25,29,30$ and 32), the arching forward of the thorax (carinated thorax or pigeon-breast) is mentioned, and, in four cases (7, 8, 20 and 24), Harrison's groove is noted.

OTHER DEFormities. Of other deformities, the testicles were undescended in all cases when they were specifically mentioned, that is, in twenty-two cases. There was some form of talipes in five cases $(18,19,25$, 29 and 32), genu valgum in one case (18) and slight double congenital dislocation of the hips in another (17). Inguinal hernia was present in two cases (14 and 15) and in one the scrotum was absent (3). In two cases (9 and 24), asymmetry of the skull was noticed, while yet others had Hirschsprung's condition of idiopathic dilatation of the colon (22) and spina bifida occulta (34). A deformity, of a different character, was the retraction of the head and neck to a right angle, in case number 30.

Abdominal skin. The outstanding character of the abdominal surface was the vertical grooving mentioned specifically in sixteen cases. In most cases, it was noted that the central one of these, that containing the umbilicus, could no be smoothed out. Transverse wrinkling of the skin was also general.

Separation of CORD. This was late in three cases $(5,11$, and 32), occurring on the nineteenth day, in the last-mentioned case. Haemorrhage was reported from the cord in the same three cases.

UmbILICUs. In most cases, this was described as a slit-like depression or scar at the bottom of the median, vertical furrow. Once it was described as being above the central point between the symphysis pubis and the xiphoid cartilage (13), but usually it was in the normal position. In case 8 , fluid was exuded from it till death intervened. The umbilicus, in case 29, admitted a probe, in the direction of the bladder, for $1 \frac{1}{5}$ inches.

Urachus. This was present in eight cases $(8,9,10,12,17,21,24$ and 29), being patent in cases 12 and 29.

Abdominal muscles. These were deficient in every case, their deficiency ranging from the highly developed abdominal herniae of case 15 to the complete absence of all the muscles of the anterior abdominal wall (10, 18, 19, 21, 22, 29, 30, 32, 33 and 34).

BLADDER. In twenty-three cases this was grossly enlarged and hypertrophied, extending upwards into the abdominal cavity as far as or nearly as far as the umbilicus. In six cases $(3,15,22,23,25$ and 31), its condition was not mentioned and in three $(6,14$ and 26$)$ it was said to be normal. In only one of these nine cases (23), was an autopsy made. 
UrETERs. These are mentioned sixteen times, being dilated, usually to a remarkable size, in fourteen cases $(4,5,8,9,11,12,13,17,20,24,27$, 28, 32 and 34) and normal in two cases (14 and 21).

Kidneys. In four cases $(9,13,17$ and 20), the left kidney was considerably larger than the right, in the first three of these the right kidney being described as of the size of a large bean. In case 34, the right kidney was slightly the larger of the two. Both kidneys were enlarged (hydronephrotic) in five cases $(4,24,27,28$ and 34), the left alone in three cases (11, 13 and 20) and the right alone in one case (8). In one or two cases, the kidneys showed some fibrosis, while case 8 had a left pyelonephrosis and case 5 an abscess in the right kidney.

Urethra. In nine cases $(4,5,12,13,17,24,27,32$ and 34) this is mentioned, as being unobstructed, but, in case 34, a ridge, projecting from the anterior wall of the prostatic urethra, is mentioned, as the probable cause of partial obstruction.

Prepuce. Mentioned, as being in a condition of phimosis, three times (11, 12 and 14) and as being free from phimosis three other times $(4,5$ and 34).

\section{Various views on the etiology of the condition.}

GUTHRIE (1896) ${ }^{5}$. In my own case, the bladder, being firmly connected with the umbilical cicatrix, has been unable to contract downwards and thus to empty itself completely. In its efforts to do so, it has been hypertrophied and dilated; urine has accumulated, causing backward pressure in the ureters and this has led to their dilatation. There is no obstruction to the outlet of the bladder that would otherwise account for the condition.

OSLer $(1901)^{7}$. (a) It is possible that the lack of resistance, normally met with in the abdominal wall by the bladder, at the time the kidneys begin to secret urine, may cause the bladder to expand rather than to empty secretions into the amniotic cavity, through the urethra.

(b) Under normal conditions, the growth of the abdominal musculature into the membrana reuniens, the early covering of the abdominal cavity, is preceded by the formation of a vascular plexus, supplied from above by the internal mammary and below by the epigastric artery. It is possible that an abnormal arrangement of the blood-vessels in the embryo prevented the formation of this plexus and impeded the growth of the abdominal musculature and that, at the same time, circulatory disturbances gave rise to the abdominal conditions found in the bladder and ureters.

Stumme (1903) ${ }^{8}$. As a result of an occlusion of the urethra, occurring fairly late in embryonic life, there was retention of urine, to which the bladder and then the ureters reacted by dilatation and hypertrophy. Owing to the pressure of the greatly dilated bladder, atrophy of the rectus abdominis occurred over a large extent, or at least, in the whole of the sub-umbilical part. In addition, there was stretching of the other abdominal muscles, that also atrophied symmetrically, probably as a result of pressure from dilated ureters. The enlargement of the bladder led to the attachment of the vertex to the umbilicus and eventually to the formation of an urachus. In addition, by pressure on the umbilical vessels, it caused, on the one hand, a diminished blood supply and therefore deficient nutrition of the embryo, and, on the other, a diminished return of blood, producing a possibility of ascites and further increase in the abdominal tension. Finally, owing to prolapse 
in front of the inguinal canal, the testicles were unable to reach the processus vaginalis to descend into the scrotum. The cause of the retention of urine disappeared later.

HaLl (1907) ${ }^{12}$. On the whole, the hypothesis of a defective development in the abdominal muscles, that thus render no assistance to the descent of the bladder and allow an abnormal direction to the ureters, at their entrance into the bladder, seems to be the most likely and to bring into line the condition of the genito-urinary organs with what appears to be fairly clearly a developmental anomaly of the abdominal muscles.

Ikeda and Stoesser (1927) 21 . With regard to our case, Professor R. E. Scammon, of the anatomy department, believes that the abdominal condition is due simply to a failure, or arrest of the embryonic skeletal muscle tissue to extend forward into the anterior body wall and therefore to develop into the abdominal musculature. What the etiological factors are that prompt the failure or arrest in the course of otherwise normal development of the embryo, we are not prepared to answer in the present communication. We are of the opinion that in our patient, at least, the hypertrophy of the bladder is probably a secondary development.

\section{Discussion.}

The association of a muscular defect of the anterior abdominal wall with striking changes in the urinary organs demands an explanation. Either one of these conditions is dependent on the other or both are due to a common cause. In the thirty-two cases, that have now been published, the bladder was described as dilated and hypertrophied twenty-three times. In six cases $(3,15,22,23,25$ and 31) it was unmentioned and in three further cases $(6,14$ and 26), it was reported as normal. Two of these (23 and 26) died, but only in the former case was a post-mortem examination made. This examination was confined to the abdominal wall, and, though the author writes, 'the muscular malformation is nearly always accompanied by undescended testicles,' he makes no mention of those glands or of the bladder, in the description of his own case. The failure to hold a post-mortem examination in case 26 was material, as this was the only case in which a defect in the abdominal wall has been reported in a female. The author, examining the infant during life, wrote ' all the organs were in their normal places and seemed normal.' Of the other two cases (6 and 14) where the bladder is mentioned, in the former it was not detected by palpation or percussion and in the latter, in addition, no resistance was found in the hypogastric region on bi-manual examination from the rectum. In this connection, it is relevant to record that, in case 16 , Mollison ${ }^{16}$ reported that the bladder could not be palpated when the boy was nineteen months old, nor yet a year later, but Spurrell ${ }^{14}$ and his co-workers, twelve years later, found that it could be felt as a pyriform swelling, extending up to and just to the right of the umbilicus. In twelve of the thirteen post-mortem examinations reported, the bladder-wall was hypertrophied and the bladder reached almost, if not quite, to the navel. Against this constant association, failure to mention the bladder, in undissected cases, cannot be taken as evidence that the bladder was normal in size and the general statement, that 
partial or complete absence of the abdominal muscles does not occur without dilatation of the bladder, is demonstrably true.

The reverse is not true. Fortescue-Brickdale ${ }^{32}$ reported three cases, seen by him in one year, of marked hypertrophy of the bladder. The ureters were dilated and tortuous and the kidneys hydronephrotic. The ages of these patients were five months, one year and two years and two months and there is nothing, in the author's paper, to suggest that the abdominal muscles were not entirely normal. Campbell ${ }^{33}$, in a study of congenital bladder-outlet obstruction, wrote:

The destructive changes, taking place in the urinary tract, above the point of obstruction, are identical .... Urinary stasis is the first ill-effect produced. This is at once followed by dilatation and hypertrophy of the urinary musculature. Trabeculation may become extreme; diverticulae frequently form, as in six of our cases. With the advent of infection, inflammatory, sclerotic atony of the bladder and ureteral walls becomes the end result. Not infrequently, the dilated, atonic ureters become as large as the colon, tortuous, sagging and oftened kinked upon themselves. Because of the marked increase in size of the ureters, on abdominal palpation, they may be thought to be intestines. Dilatation of the kidney pelvis, with compression and thinning-out of the renal parenchyma, follows.

That might well be a description of case 34 , but the abdominal muscles, in all the cases described by Campbell, were normal.

It can be said, then, with little fear of error, that, though dilatation of the bladder frequently occurs without an associated defect of the abdominal muscles, absence of those muscles never occurs apart from dilatation of the bladder. In other words, the muscular defect is secondary to dilatation of the bladder.

The second problem, set by these cases, is to form an accurate idea of the progress of the abdominal muscles. Is there a real agenesis, or is their absence due to the atrophy of previously formed muscles.

It is instructive to combine the descriptions of the abdominal musculature, in the complete series of cases. The frequency with which the various muscles are absent is found to be the transversus abdominis (25 times), the rectus, below the navel (24 times), the internal oblique (23 times), the external oblique (21 times) and the rectus, above the navel (12 times. In no case was the transversus or internal oblique muscle present as a muscle, though, in cases 4 and 7 , traces or remains of the muscles were found at their origins and insertions. The external oblique was only present as such in one case, though remnants remained in eight other cases, but the rectus was present, as a muscle, in nine cases above the navel and in four cases, below it. In nine further cases, this muscle was present, though very reduced in size, above the navel and, in three cases, below the navel. In case 23, the upper half of each rectus was stated to be less-formed than its lower half. The recorder of case 19 was of the opinion that, in this infant, the diaphragm was absent. The quadratus lumborum was absent in two cases and very much reduced in thickness in five others.

This combination of descriptions shows that the thin, sheet-like muscles (the obliqui and transversales) were those most frequently absent, the stronger, thicker rectus muscle often being present, in their absence, 
especially above the navel. It also shows the tendency for these muscies to disappear from within outwards, the transversus abdominis going first, followed by the obliquus internus and the obliquus externus, in that order.

In some cases, where the muscles were macroscopically absent, evidence was obtained by examining the subcutaneous tissues. In case 5 , the costal origins of the obliqui and transversus, on each side, showed muscular structures for about two fingers' breadths below the ribs. Here they were lost, but reappeared in the iliac regions, where they formed a tense band of three layers, corresponding to the external and internal obliques and transversus, but the last two existed only as scattered and extremely thin muscular strands. In case 9, on microscopical examination, the fibres of the aponeuroses of the muscles, that formed a very striking feature in normal sections, were almost entirely absent. In case 13, on microscopical examination of a transverse section of the anterior abdominal wall, above the umbilicus, three layers of connective tissue were found deep to the skin. These were the superficial fascia and two deeper, thicker layers, representing the aponeurosis of the external oblique and the anterior layer of the internal oblique aponeurosis. Deep to this came a very small rectus muscle, lying on a double layer of connective tissue-the posterior layer of the internal oblique and the transversus aponeuroses. The transversalis fascia could not be found. A comparison of the section with one from a normal eightmonths foetus, convinced the author regarding the identity of the layers described. In case 21 , sections, lateral to the middle line, revealed some evidence of definite fascial planes, but no evidence of muscular tissue. The conclusion to be drawn from these four cases, is that, after the total disappearance of the muscles, the fascia remains in recognizable layers, in those cases where the thinning of the subcutaneous tissues has not become extreme.

Further evidence is contained in the microscopical study of the sprinkling of fibres left in some cases of macroscopical absence. In case 9, the muscular layer contained what appeared to be undeveloped muscle-fibres, irregularly arranged. These were identified as muscle-fibres by the shape of the bundles and the arrangement of the fibres, the shape and striation of normal fibres being absent. The nuclei were elongated and rod-shaped and seemed to occupy the centres of unstriped muscle-fibres or fibres in the early stage of development. It would appear that arrest of development in the abdominal muscles had occurred at an early age of their foetal life. There was nothing to suggest that atrophy of a normally-developed muscle had taken place.

In case 11, an examination of the normal muscular zones, below the level of the umbilicus, showed a narrow zone of loose fibrous tissue, containing rather darkly-stained, round and oval nuclei. These stood out, in marked contrast to the elongated and irregular nuclei of the normal connective tissue. Some of these nuclei were surrounded by a more or less definite zone of protoplasm, the whole cell being of considerable size. A few of the cells had horse-shoe or kidney-shaped nuclei, but their general appearance did not suggest a vascular origin. Their exact nature was very 
doubtful, but they did not appear to resemble the cells of muscular tissue that had undergone a regressive change. In the rectus, above the umbilicus, the muscle-fibres were unnaturally rounded and less closely packed than in normal muscle, while their average size was somewhat greater, some fibres being definitely swollen. The sparseness of muscle-fibres in the well-developed parts, the absence of definite nuclear proliferation in the rectus region below the umbilicus, and the absence of any connective tissue increase, such as would probably have resulted from the disappearance of already developed fibres, all seemed to indicate that the condition was an anomaly of early developmental origin. This author reminds us that the sarcolemma sheath, that with the sarcoplastic nuclei develops into fibrous or fatty tissue in retrogressive muscular changes, appears first at about the time of birth. In case 13 , where the rectus muscle was missing, its place was taken by a coarsefibred, tendinous formation with transverse nuclei. In case 20 , the existing muscle-fibres appeared to be normal.

Whatever view be taken of these descriptions, it must be evident that muscle once present has actually disappeared. It remains to discover why.

The theory that the condition is due to a prenatal anterior poliomyelitis has been disproved. Cell-counts in the anterior horns of the thoracic spinal cord, particularly complete in the first case, were made in cases 9 and 11 , without lending any support to this theory.

The absence of abdominal muscles may be caused by a hypertrophied bladder in one of two ways. The ventral bulging of the bladder may prevent the muscles from forming at all, except at the periphery of the abdominal cavity or the pressure of its dilatation on already-formed muscles, may cause them to atrophy. In this respect, the time-relationship between the formation of the muscles and the bladder, becomes an important factor. If the muscles be prevented from forming over the ventral surface of the abdomen by a distended bladder, then that organ must be a closed, hollow viscus into which the kidneys are secreting urine, before the normal time of formation of the muscles.

The bladder is formed from the ventral division of the cloaca, the cranial end of which division becomes drawn out in continuation with the allantoic remnant in the cord. At its caudal end, the same division does not dilate, but forms the upper part of the prostatic urethra in men, and the whole of that passage in women. In the third month of gestation this sausage-like shape of the bladder is very evident. The foetal excretion can pass from the bladder, either through the urachus into the allantoic liquid, or through the urethra into the amniotic liquid. According to Needham ${ }^{34}$, Jacque found by experiment that up to a foetal length of $20 \mathrm{~cm}$. (approximate the middle of the seventh week), the allantoic liquid was the sole recipient of the urine and that, after $32 \mathrm{~cm}$. (approximately the early part of the ninth week), the amniotic liquid alone received it. Between those two ages urine was excreted into both allantoic and amniotic sacs. The intermediate period varied with a number of factors, among them being the sex of the embryo, 
the male urethra being more tortuous and offering more resistance to fluids passing through it than that of the females. Needham notes that the appearance and physical properties of the two fluids agree entirely with the facts, the amniotic fluid, before the $20 \mathrm{~cm}$. length, being clear and transparent, later become cloudy and mucilaginous. It may be taken as sufficiently accurate that urine will be excreted through the urethra from the early part of the ninth week. If through some cause this cannot be, urine will collect in the bladder, which will slowly dilate, the only other outlet, the allantoic canal, being already almost obliterated. Now if the ventral abdominal muscles are to be prevented from forming at all, that is if there is to be a real agenesis, this condition of the bladder must be reached before the muscle sheets formed by the ventral down-growths of the myotomes have grown round towards the umbilical sac. Frazer ${ }^{35}$ shows, however, that the three muscles of the lateral abdominal wall are distinguishable at the end of the fifth or beginning of the sixth week and that, by the time the gut in the umbilical sac is ready to withdraw into the abdomen at the end of the ninth week, the two recti are already constricting the opening of the sac, closing it quickly upon the gut's withdrawal. It seems certain, then, that the abdominal muscles are formed before pressure can be exerted on them by the distended bladder and the evidence suggests that it is pressure, both direct on the muscle-fibres and indirect on the blood-vessels, that causes anaemia and death of the muscle-fibres. As was suggested by Stumme ${ }^{8}$, the increased abdominal tension may impede the venous flow in the portal system of veins, the consequent ascites still further increasing the pressure on the abdominal walls. It is possible that the frequent remains of the rectus, found above the umbilicus, were due to the greater protection from pressure afforded to its blood-supply.

The last problem seems to be to find out why the outflow from the bladder through the urethra is obstructed in these cases. Two answers suggest themselves. The impediment is either a neuro-muscular incoordination (an achalasia of the vesico-urethral orifice) or it is a definite organic obstruction. Fortescue-Brickdale ${ }^{32}$, in reporting three cases of congenital dilatation of the ureters, regarded each of them as due to the primary hyperplasia of the bladder wall, ' due possibly to disordered nervous influence.' In each case a catheter was easily passed after death and no evidence of a urethral valve or other cause of obstruction to the urethra could be discovered on dissection. As in eight of the cases reported in the present study, there was no organic obstruction to the passage of urine, sounds or catheters, a neuro-muscular incoordination is a possible solution. In the case reported above, however, urine was freely passed and a catheter was passed into the bladder during life without difficultv, yet, on nost-mortem dissection, a most definite, organic obstruction was discovered nrojecting from the anterior wall of the lower part of the prostatic urethra. This projectino ridoe had evidently once caused a complete obstruction of the bladder until the hvnertronhied muscle of that oroan had dilated the nner part of the prostatic wrethra. and forced a nassage for the urine past 
the obstruction. In how many cases, where the urethra was permeable to urine and catheters but was not examined by dissection, might similar organic obstructions have been found? In at least one case (24), the dissection may still be made, for an undissected penis is attached to the specimen in the museum of the Hospital for Sick Children, Great Ormond Street.

Of the dilatation of the ureters and kidneys, there is little to say. Hurst and Gaymer-Jones ${ }^{36}$ have reported a case of megalo-ureter due to achalasia of the uretero-vesical sphincter and have discovered two others in the literature, but in cases where a powerful, hypertrophied bladder muscle was contracting, in an endeavour to force the urethral obstruction, there could have been little chance for the urine to force its way from the ureter into the bladder. Dilatation of the ureter would have followed, the pelvis and calyces of the kidney dilating last of all.

The last general abnormality, the non-descent of the testes, is readily explained. The testis descends with the vaginal sac of the peritoneum in the seventh month and reaches the scrotum by the end of the eighth month. Long before this, in cases of congenital absence of the abdominal muscles, the road to the internal inguinal ring is blocked by the enormous bladder and ureters.

\section{Summary.}

1. A description is given of a case of congenital absence of the abdominal muscles.

2. A summary of the salient points of thirty-four published cases is given.

3. Various views on the cause of the condition are described and it is shown, in a discussion, that the absence of the abdominal muscles is due to the atrophy of previously-formed muscles, by pressure from an enormously dilated bladder and ureters, such pressure being probably increased by secondary ascites. The cause of the dilatation and hypertrophy of the bladder is considered to be an organic obstruction in the urethra.

It is a pleasure to acknowledge the help received from Dr. H. Radford Potter, who took the photograph used in fig. 1, from Dr. Jagger, who is responsible for the skiagrams, and to Mr. T. W. P. Lawrence, of the Royal College of Surgeons Museum, who examined and discussed the condition of the urinary organs.

\section{BIBLIOGR A PHY.}

1. Fröhlich, Der Mangel der muskeln inbesondere der Seitenbauchmuskeln, Dissertation, Wurzburg, 1839.

2. Ammon, F. A. v., Die angeborenen chirurgischen Krankheiten des Menschen, 1842, 59.

3. Henderson, B., Glasgow Med. J., Glasgow, 1890, XXXIII, 63.

4. Parker, R. W., Trans. Clin. Soc. Lond., London, 1895, XXVIII, 201.

5. Guthrie, L., Trans. Path. Soc. Lond., London, 1896, XLVII, 139.

6. Platt, W. B., Philad. Med. J., Philadelph., 1898, I, 738.

7. Osler, W., Bull. Johns Hopkins Hosp., Baltimore, 1901, XII, 331, 
8. Stumme, E. G., Mitt. a. d. Grenzgeb. d. Med. u. Chir., Jena, 1903, XI, 548. (Abstract, Centralbl. f. allg. Path. u. path. Anat., Jena, 1904, XV, 412.)

9. Garrod, A. E., \& Davies, Ll. W., Medico-Chir. Trans., London, 1905, LXXXVIII, 363.

10. Parsons, L. G., \& Barling, S., Diseases of Infancy \& Childhood, London, 1933, II, 1404.

11. Bolton, C., Trans. Clin. Soc. Lond., London, 1905, XXXVIII, 247.

12. Hall, G., Lancet, London, 1907, ii, 1672.

13. Pels-Leusden, F., Arch. f. klin. Chir., Berlin, 1908, LXXXV, 392. (Abstr. Schmidt's Jahrb., Bonn, 1908, CCXCVIII, 239.)

14. Mackeith, N. W., et. al., Guy's Hosp. Rep., London, 1923, LXXIII, 479.

15. Levy, R., Beitr. z. klin. Chir., Berlin, 1908, LVII, 201. (Abstr., Zentralbl. f. Chir., Leipzig, 1908, XXXV, 1035.)

16. Mollison, W. M., Guy's Hosp. Rep., London, 1909, LXIII, 23.

17. Thatcher, L., Edinburgh Med. J., Edin., 1913, XI, (n. s.), 127.

18. Smith, Bellingham E., Proc. Roy. Soc. Med., London, 1913, VI, 186.

19. Stern, A., Archiv. Diagnosis, New York, 1915, VIII, 73.

20. Eckhoff, N. L., Guy's Hosp. Rep., London, 1923, LXXIII, 490.

21. Ikeda, K., \& Stoesser, A. V., Am. J. Dis. Child., Chicago, 1927, XXXIII, 286.

22. Blasi, D., Pediatria, Naples, 1927, XXXV, 720. (Abstr., Monatschr. f. Kinderh., Berlin, 1928, XXXVIII, 441.)

23. Taillens, J., Bull. Soc. de pédiat. de Paris, Paris, 1928, XXVI, 277.

24. Moncrieff, A., Brit. J. Child. Dis., London, 1931, XXVIII, 220.

25. Brindeau, M., \& Jacquet, E.,. Bull. Soc. d'Obst. et de Gynéc., Paris, 1923, XVII, 826.

26. Hofstein, J., Gynéc. et Obstét., Paris, 1930, XXII, 23.

27. Friedly, R. S., The Ohio State Med. J., Columbus, 1932, XXVIII, 843.

28. Malossi, C., \& Galli, G., Lattante, Parma, 1931, II, 69. (Abstr. Zentralbl. f. d ges. Kinderh., Berlin, 1931, XXV, 527.)

29. Baxter, E. H., The Ohio State Med. J., Columbus, 1932, XXVIII, 840.

30. Stcesser, A. V., Arch. of Ped., 1933, New York, L, 739.

31. Gibbens, J., Brit. J. Child. Dis., London, 1934, XXXI, 43.

32. Fortescue-Brickdale, J. M., Brist. Medico-Chir. J., Bristol, 1905, XXIII, 230.

33. Campbell, M. F., New York State J. Med., New York, 1930, XXX, 704.

34. Needham, J., Chemical Embryology, Camb., III, 1551.

35. Frazer, J. E., A Manual of Embryology, London, 1931, 122.

36. Hurst, A. F., \& Gaymer-Jones, J., Guy's Hosp. Rep., London, 1930, LXXX, 334. 